\title{
Phase Model of Asset Crises Identification
}

\author{
Vera Ivanyuk
}

\begin{abstract}
The study is devoted to an econometric model development for the asset crises identification. Unlike the classical approach, the economic crisis is considered not as a one-time state (for example, the point of bifurcation in Krugman's equilibrium crisis model or the market oversaturation moment in Marx's theory), but as a process that continues in time. A method for crisis initial phase early identification is developed. To identify a systemic crisis, an ANOVA based indicator is proposed.
\end{abstract}

\section{Introduction}

Economic crises have been the subject of long-term scientific research by such prominent economists as Karl Marx [1] who insisted on their inevitability, John Maynard Keynes [2] who declared the possibility of a crisis-free economy, Israel Kirzner [3] who emphasized the excessive subjectivity of models of the above authors, Paul Krugman [4] who suggested the crisis model that came to be seen as conventional.

In the modern model of crisis, Phornchanok Cumperayot. and Roy Kouwenberg [5] suggest a quantitative method of the crisis evaluation based on the data of financial indicators of monthly currency exchange rates. Pearpilai Jutasompakorn et al. [6] point out three market conditions - growth, decline and crisis - as separate qualitative categories and focus on banking crisis identification. A model of crisis is offered by Andrei Korobeinikov who in his research [7] describes crisis as a catastrophic epidemic of bankruptcies. The analysis of existing crisis models makes evident their shortcomings, specifically, low-level abstract models demonstrate excessive concretization expressed in the consideration of crisis in the context of the beginning of the asset value collapse as a fait accompli. However, the specific changes proposed by the authors of the models [5], [6] as attributes of a crisis situation expressed in absolute numerical terms do not in the least guarantee the actual presence of crisis and are not well substantiated, neither statistically nor mathematically. At

Manuscript received May 13, 2018; accepted January 30, 2019.

Vera Ivanyuk is with the Financial University under the Government of the Russian Federation, 38 Shcherbakovskaya St., Moscow 105187, Russia 
the same time, the point estimation bankruptcy $=$ crisis, no bankruptcy $=$ no crisis, used in the model of Andrei Korobeinikov [7] without due mathematical or econometric justification also makes this technique inapplicable in practice. Thus, it is necessary to develop the author's own crisis indicator which would ensure a statistically significant characterization of crisis and a high practical relevance.

In contrast to the classical approach, the author's approach considers crisis not as a non-recurrent state, for example, the bifurcation point in the equilibrium model of crisis of Paul Krugman [4] or the point of market saturation in the theory of Karl Marx [1] but as an ongoing process of phase transition in a cyclically varying open system representing the imbalance of supply and demand parameters [8].

The author's approach is to design a mathematical model of crisis development which allows predicting the crisis risks.

\section{Identification of the crisis based on the modified Fisher's test}

The global liquidity deficit, overvalued, little liquid assets and derivative financial instruments on the market have led to a situation, when the world economy, depending on the volume of liquidity, became subject to chain-consistent global crises. Only for the last 15 years the continuous series of crises were observed in the world.

So, the crisis is not an instantaneous and unexpected process, but an inalienable property of the economic system, by the way it has a certain speed of development. According to I. R. Prigozhin, the beginning of the crisis can't be predicted. But if the crisis has already begun, you can identify it at an early stage and predict further development.

To develop an indicator that determines the crisis at an early stage. The crisis indicator is based on the analysis of variance (ANOVA). As a crisis indicator, the modified Fisher's criterion $H\left(\sigma_{\tau}-3 \sigma\right)$. is the most preferred. The modified Fischer's criterion is based on the assumption that the long-term (saved-up) variability of an asset corresponds sigma, and on exit of short-term variability for borders in three standard deviations the condition of system corresponds to crisis with probability of $97,3 \%$. Figures $1-2$ show the results of experiments. 


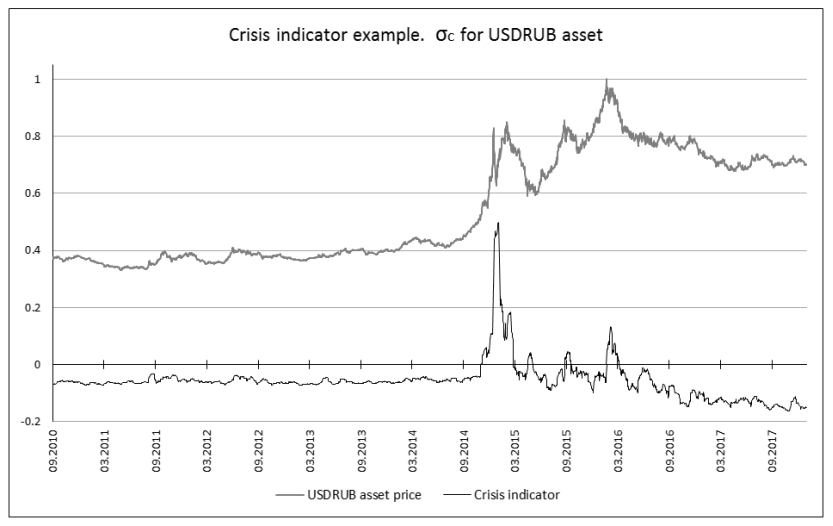

Fig. 1. Identification of the crisis based on the modified Fisher's test by the example of USD/RUB for the period from 01.09.2010 to 01.09.2017

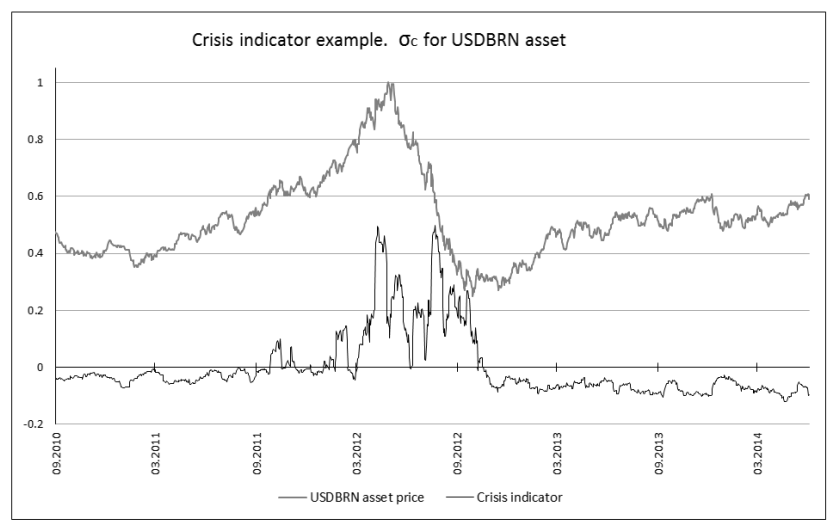

Fig. 2. Identification of the crisis based on the modified Fisher's test by the example of Brent crude oil price for the period from 01.09.2010 to 01.09.2014

\section{Experiment to develop and test the quality of crisis variability phase model of a MOEX asset}

The aim of the experiment: to create a statistically valuable crisis phase model of a MOEX asset.

1. We use a sample of 98 asset variability values in times of crisis normalized according to the maximum time series, normalized according to the value and time with a permissible error no more than 0,025 , equal to $\frac{\alpha}{2}$ for $\alpha=0,05$. 
2. In the model analysis, we will define the main shaping factors as the average normalized value of crisis variability $\bar{\sigma}_{H}(t)$, which is equal to the value of $\overline{H\left(\sigma_{\tau}(t)-3 \sigma(t)\right) *\left(\sigma_{\tau}(t)-3 \sigma(t)\right)}$ and mean standard deviation of time series variability $\sigma_{\sigma_{H}}$.

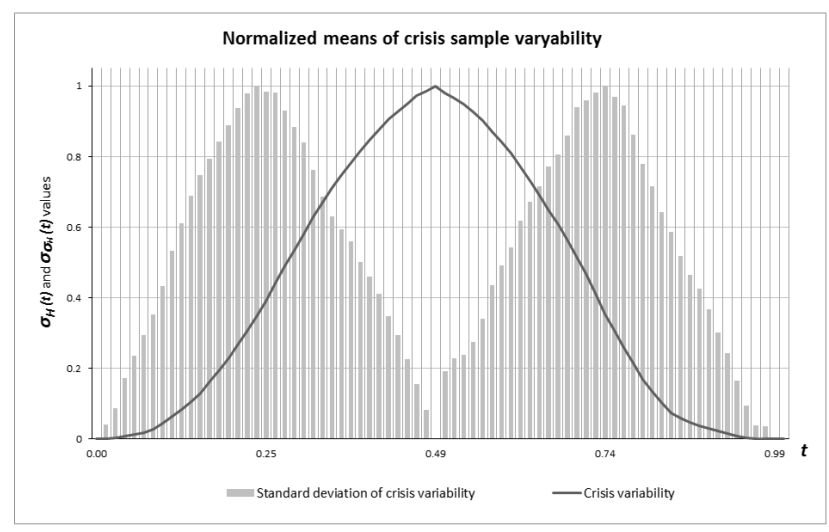

Fig. 3. Crisis variability

To build a model function of $\sigma_{H}(t) \pm \sigma_{\sigma_{H}}$ type in unbiased phase, phase conformity $\varphi\left(\sigma_{H}(t)\right) \widehat{=} \pi ; \varphi\left(\sigma_{\sigma_{H}}\right) \widehat{=} 2 \pi$ will be true.

3. We will represent $\sigma_{H}$ and $\sigma_{\sigma_{H}}$ as exponents of periodic functions in $a$ simplified way:

$$
\sigma_{H}(t)=a_{1}(\sin \mathrm{t})^{b_{1}} ; \sigma_{\sigma_{H}}(t)=a_{2}|\sin 2 \mathrm{t}|^{b_{2}}
$$

4. By using reduced gradient method, we will carry out an approximation of estimated values $\overline{\sigma_{H}(t)}$ and $\sigma_{\sigma_{H}}(t)$ to calculate the values of coefficients $a$ and $b$ with functions $a_{1}(\sin \mathrm{t})^{b_{1}}$ and $a_{2}|\sin 2 \mathrm{t}|^{b_{2}}$, respectively (Figure 4).

5. As a result, we have the following values:

$$
a_{1}=0.989 ; b_{1}=2.543 ; a_{2}=0.254 ; b_{2}=1.135 ;
$$

6. Consequently, crisis variability can be described as follows: 


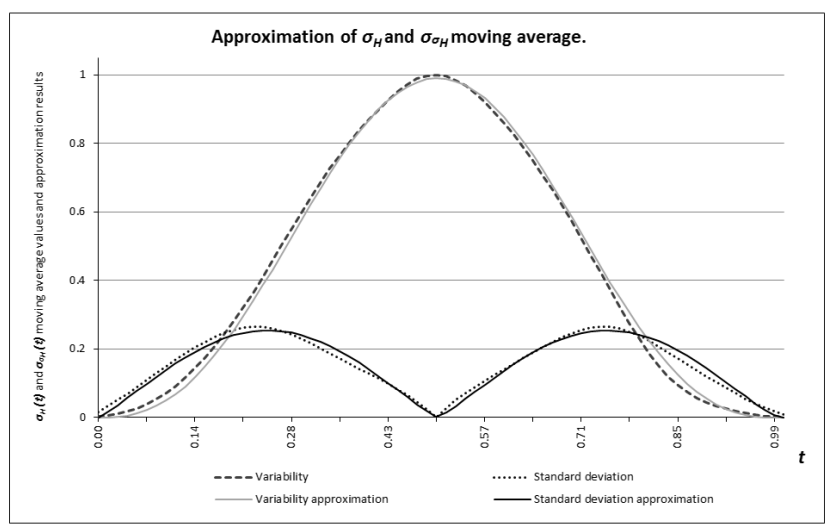

Fig. 4. Approximation $\overline{\sigma_{H}(t)}$ and $\sigma_{\sigma_{H}}(t)$ moving average

Table 1. Crisis development phases of a MOEX strategic asset

\begin{tabular}{|c|c|c|c|c|c|}
\hline Type & Name & $\sigma_{H}(t)$ & $\sigma_{H}^{\prime}(t)$ & $\sigma_{H}^{\prime \prime}(t)$ & $t$ \\
\hline point & Beginning of crisis & $\approx 0$ & $>0$ & $>0$ & $\approx 0$ \\
\hline phase & Growth increase & ] $0 ; 1[$ & & & ] $0 ; 0,3[$ \\
\hline point & Dynamics & & & $\approx 0$ & $\approx 0,3$ \\
\hline phase & Growth decrease & & & $<0$ & ] 0,$3 ; 0,5[$ \\
\hline point & Crisis & $\approx 1$ & $\approx 0$ & & $\approx 0,5$ \\
\hline phase & Downturn increase & ] $0 ; 1[$ & $<0$ & & ] 0,$5 ; 0,7[$ \\
\hline point & Dynamics & & & $\approx 0$ & $\approx 0,7$ \\
\hline phase & Downturn decrease & & & $>0$ & ] 0,$7 ; 1[$ \\
\hline point & End of crisis & $\approx 0$ & & & $\approx 1$ \\
\hline
\end{tabular}

$$
\sigma_{H}(t)=0.989(\sin \mathrm{t})^{2.543} \pm 0.254|\sin 2 \mathrm{t}|^{1.135} \quad t \in[0 ; 1]
$$

Since the model is based on the implicit assumption about the compliance $\varphi(\overline{x(t)}) \widehat{=} \pi ; \varphi\left(\overline{\sigma_{\sigma}(t)}\right) \widehat{=} 2 \pi$, it is necessary to carry out a statistical assessment of the quality of the model for set $\alpha=0,05$.

\section{Conclusions}

In this statistical research, we have created a phase model of stock-market asset crisis development. This model meets the quality requirements for set $\alpha=0.05$ and helps define crisis and its current phase as well as provides an opportunity to forecast crisis price fluctuations of an asset by reflecting the occurring risks. 
Figure 5 shows a risk forecast on EUR/RUB currency pair.

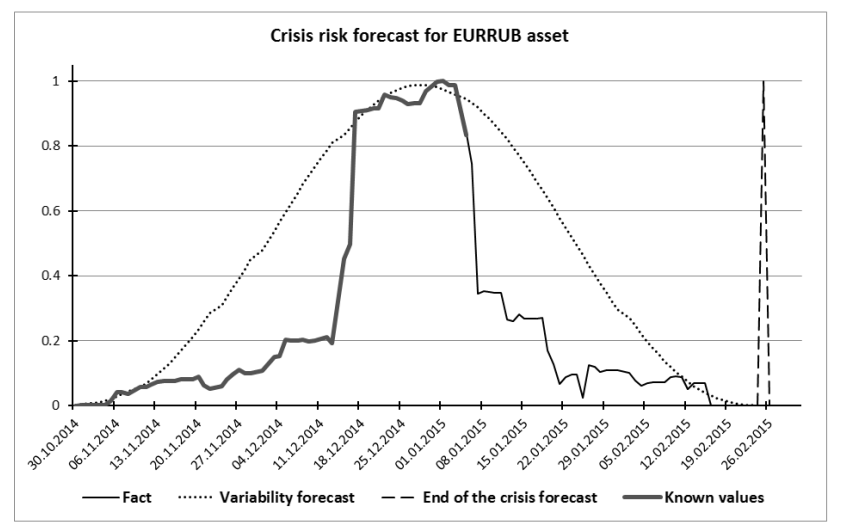

Fig. 5. EUR/RUB risk forecast in the crisis period

To conclude, a crisis indicator has been synthesized and a model for the development of the crisis process has been formulated that have both a sufficient level of generalization and significant reliability of the characteristics, which are responsible for determining the economic crisis. The validity of this model, the possibility or impossibility of applying the statistical apparatus to the forecast of volatility development theoretically and practically make it more effective than existing models.

\section{References}

[1] K. MARX, Economic and philosophical manuscripts of 1844. in Early Writings, London, Penguin Books, 1975.

[2] J. M. KEYNES, The general theory of employment, interest, and money, Springer, 2018.

[3] I. M. KIRZNER, Subjectivism, intelligibility and economic understanding: essays in honor of Ludwig M. Lachmann on his eightieth birthday, New York University Press New York, 1986.

[4] P. R. KRugman, The return of depression economics, WW Norton \& Company, 2000.

[5] P. Cumperayot R. KouWEnBerg, Early warning systems for currency crises: A multivariate extreme value approach, Journal of international money and finance, 36 (2013) 151-171, 2013.

[6] P. Jutasompakorn, R. Brooks, C. Brown, S. Treepongkaruna, Banking crises: Identifying dates and determinants, Journal of International Financial Markets, Institutions and Money, 32 (2014) 150-166.

[7] A. Korobeinikov, Financial crisis: An attempt of mathematical modelling, Applied Mathematics Letters, 22 (2009) 1882-1886.

[8] G. Nicoli, I. Prigogine, G. Nocolis,Exploring complexity, St. Martin's Press, 1989. 